\title{
De Chiapas a California. Experiencia migratoria y cambio cultural en jóvenes indígenas ${ }^{1}$
}

\section{From Chiapas to California: Indigenous Youth's Migratory Experience and Cultural Change}

\author{
Tania Cruz Salazar \\ El Colegio de la Frontera Sur, \\ email: tcruzs@ecosur.mx
}

Resumen:

Documento, desde una perspectiva etnográfica, la experiencia migratoria internacional de jóvenes indígenas chiapanecos y sus adaptaciones culturales. Sostengo que la participación de la juventud indígena ha sido central para el desarrollo económico del estado, y esto tiene sus orígenes en la tradicional migración indígena interna (siglo XIX) y nacional (siglo XX) protagonizada en su tiempo por quienes hoy son los abuelos o padres. Para las actuales generaciones, la migración internacional, aunque aún es una estrategia económica, ya no es temporal como lo fue al inicio, por lo que su estadía en los Estados Unidos les implica cambios a nivel subjetivo, comunitario y cultural. Es en estos panoramas que analizo aquello que cambia y permanece.

Palabras claves: migración, espacios multiculturales, juventud indígena, identidad étnica, generaciones.

Abstract:

This article uses an ethnographic perspective to document the international migratory experience of indigenous youth from Chiapas State and their cultural adaptation. It posits that indigenous youth participation has been of key importance to the state's economic development. This phenomenon has its origin in traditional internal (nineteenth century) and national (twentieth century) indigenous migration by grandparents or parents. For current generations, although international migration continues to be an economic strategy, it is no longer temporary as before, which is why their stay in the United States now implies subjective, community and cultural changes. What changes and what remains the same are thus analyzed within this context.

Keywords: migration, multicultural spaces, indigenous youth, ethnic identity, generations.

1 En este artículo el término indígena hace referencia a personas de distintos grupos étnicos en México y en especial a las chiapanecas hablantes de distintas lenguas: tsotsil, tseltal, ch'ol, ch'olano-tseltal y maya-lacandón. 


\section{Introducción}

\section{Lenas}

a experiencia migratoria comprende aprendizajes, nuevas interpretaciones, creencias, valores, «prácticas culturales, económicas y políticas de actores individuales o colectivos dentro de territorios o lugares» definidos por comunidades socioculturales (Faist 2004:4, mi traducción). El caso de los jóvenes tseltales y choles chiapanecos en California indica que sus nociones espaciotemporales se amplían al asentarse en un nuevo territorio donde su cotidianidad tiene lógicas multifocales y, sobre todo, multiculturales. El nuevo espacio social se define en primer lugar con los miembros de la comunidad de origen, ubicados tanto en el lugar de acogida como en el terruño, en la frontera y en otros lados de los Estados Unidos; en segundo lugar, con los personajes que procuran la contratación, y en tercero, con el resto de la población en el lugar de acogida que son actores propios de lo local en otras instituciones que procuran la integración social, léase: escuela, iglesia y vecindad o colonia. Aquí me referiré solo al primer lugar que muestra la reproducción comunitaria, el lugar de origen replicado en el lugar de acogida, en California. Así que la experiencia migratoria remite a esa visión de mundo cambiante en estos grupos culturales que transitan a la adultez en una cultura disímil a la de origen en términos étnicos y de género. Para entender, entonces, la dimensión instrumental de las identidades presté atención al incremento de repertorios culturales y lazos sociales. En ciudades multiculturales donde la diversidad étnico-cultural es amplia, también lo son las tensiones y los conflictos; de modo que la identidad juega un rol determinante en términos de diferencia cultural. Si observamos los procesos de urbanización y gentrificación actuales, la articulación de identidades en la migración sirve para el grupo referencial que se repiensa y readapta a partir de otras creencias y valores en el lugar de acogida, lo que en ocasiones significa alteraciones culturales: ¿cómo la experiencia migratoria impacta culturalmente en la identidad étnica de un grupo de jóvenes tseltales y choles chiapanecos radicados en California? Este trabajo intenta responder a dicho cuestionamiento ofreciendo una lectura económico-cultural sobre las relaciones Chiapas-Estados Unidos a partir de las vivencias de estos jóvenes con una primera sistematización del trabajo de campo realizado en la California estadounidense. 


\section{Apartado metodológico}

Con base en el método etnográfico, apunto sintéticamente los principales hallazgos de la migración de jóvenes indígenas chiapanecos; hablo de los nuevos actores involucrados en el proceso migratorio, los cambios en las relaciones de pareja entre dos generaciones de migrantes y los nuevos usos y modificaciones de la lengua entre los más jóvenes. La indagación transcurrió en cuatro etapas, a lo largo de 18 meses. La primera fue explorativa y afianzó contactos desde Chiapas; la siguiente implicó mi arribo a las ciudades californianas para explorar la presencia de chiapanecos y sus relaciones con otras comunidades de inmigrantes sureños; la tercera fue sobre el tejido fino del asentamiento de los grupos en las ciudades, así como de su participación laboral en ciertos sectores productivos y su identificación étnica; y la última se centró en la selección de los colaboradores y estuvo orientada por entrevistas semiestructuradas y a profundidad. Los contextos en los que se desenvolvieron las conversaciones fueron cambiando, y estas, volviéndose más estrechas.

De 2011 a 2013, bajo el auspicio de la Universidad de California, el Instituto México- Estados Unidos y el Consejo Nacional de Ciencia y Tecnología, hice una estancia de investigación posdoctoral en la Universidad de California en Santa Cruz, la cual financió parte del trabajo de campo. Este tuvo sus inicios en 2008, en Chiapas, cuando por medio de estudiantes de la Universidad Autónoma de Chiapas (UNACH) y la Universidad Intercultural de Chiapas (UNICH) establecí los primeros contactos con sus familiares en California y otros estados del país vecino. Luego de haber sido presentada y recomendada vía telefónica, tres años después llegué a San José, California, donde conocí a los primeros dos jóvenes tseltales de Chancalá, primos de uno de mis exestudiantes de la UNICH. Tres meses después logré tejer una red de tseltales y choles entre Los Ángeles y San José, California. Tardé un año para registrar la presencia de tres comunidades: la más grande y consolidada en San Francisco, la media en Los Ángeles y la más pequeña en San José. En total fueron 106 personas que agrupé en tres generaciones, incluyendo los 18 niños hijos de los 88 entrevistados (21 adultos y 67 jóvenes); 66 varones y 14 mujeres. Realicé entrevistas abiertas y a profundidad, una encuesta, conversaciones informales, grupos focales y una intensa observación participante. Descubrí que su elemento identitario era la pertenencia al ejido o a la comunidad como el eje de adscripción más importante al grupo o la red de apoyo en California. La mayoría de los entrevistados provenían de la región Selva 
y la minoría del centro de la región Altos, todos hablantes de español como segundo idioma y también con conocimientos del inglés. 73 hablan solo tseltal; 13, ch'ol y tseltal; y tres, maya-lacandón y maya-tseltal. Asistieron a la primaria 19; se inscribieron a la secundaria 51 y 17 la terminaron; solo uno de ellos inició estudios universitarios sin concluirlos; 36 son padres y 4 son madres; 57 eran solteros, 28 estaban casados y uno divorciado. En este texto todos los nombres de los entrevistados son ficticios.

\section{Antecedentes}

La experiencia tradicional de la migración tsotsil se consolidó en 1890, cuando los campesinos abandonaron sus hogares y fueron a trabajar temporalmente en las plantaciones de café. Esta migración fue de los Altos hacia el Soconusco y resultó ser la principal razón para la subsistencia de la comunidad tsotsil desde 1910 hasta mediados de los setenta, cuando los tsotsiles fueron reemplazados por modernas técnicas de agricultura y por el colapso de las plantaciones agrícolas (Rus y Collier 2002, Rus 2010).

Con la crisis agraria de 1988, el levantamiento armado del Ejército Zapatista de Liberación Nacional (EZLN), la llegada del Tratado de Libre Comercio de América del Norte (TLCAN) en 1994 y los desastres naturales provocados por el huracán Mitch en 1998 y Stan en 2005 emergieron generaciones de indígenas sin tierra o sin insumos para trabajarla, sin empleo y algunos hasta sin esperanzas para la vida comunal. La década de los noventa fue paradigmática pues trajo alteraciones económicas, sociales y políticas que convencieron a los habitantes de los Altos y la Selva de irse al norte (Estados Unidos). El desaliento comunitario vino después del 94, cuando el sentimiento de pertenencia perdió legitimación y no se pudo seguir manteniendo la vida comunal basada en valores, ideologías y prácticas particulares de los colonos (Leyva 2002).

Antes del levantamiento zapatista el movimiento logró atraer y mantener la participación de colonos, quienes lucharon convencidos y mantuvieron vivo el sentimiento de comunidad expresado en la militancia durante una década. Pero esa convicción se desvaneció y transformó entre 1995 y 1998. Tomar las tierras de los ricos hacendados fue uno de los objetivos del proyecto zapatista para mantener a la gente unida y con los «cuatro caminos» de la Asociación Rural de Interés Colectivo (ARIC): «la fe católica, las ideologías guevaristas, las maoístas, y 
la oposición a los 'caxlanes' o 'ladinos'» (Leyva 2002:59) que funcionó para algunos como motivos de unión y de lucha. Sin embargo, la exigencia de un compromiso sustentado por el orgullo indígena y la determinación política fue difícil de cumplir y sostener a través de los años. Para los zapatistas, los proyectos de los jóvenes migrantes retaban la esencia del movimiento, así que tuvieron que discutir el caso y aceptar que sus metas no eran de interés para las expectativas de la nueva generación. La primera y segunda generación de zapatistas vieron en el movimiento un significado totalmente diferente. A mi pregunta, ¿qué piensas acerca del movimiento zapatista?, Cirilo, un joven tseltal, respondió: «nada, por un tiempo pensé que era chido, pero luego pasó de moda». Al comparar esa opinión con la de Timoteo, un tseltal de 35 años, originario de Chancalá, se perciben impactos totalmente diferentes en generaciones previas y posteriores, puesto que este último siente el compromiso de adherirse al movimiento en el caso de su eventual reactivación o de un nuevo levantamiento en armas: "yo firmé un acuerdo, un permiso, entonces cuando vuelva, si es necesario, me voy a las armas de nuevo». Cirilo, en cambio, no comparte ese compromiso hacia el movimiento, ya que si se volvieran a levantar no se uniría a ellos, aunque le encante vestir la camiseta negra con la cara de Marcos impresa al frente y decir muy orgulloso: «soy indígena de la Lacandona».

Los conflictos comunales entre los zapatistas de la primera generación y los deseos de los jóvenes de dirigirse hacia el norte reflejan lo que Aquino (2009:79-95) llama «la lógica militante» vs «la lógica migrante» para explicar cómo la primera ve una redención entre sus camaradas que parten hacia los Estados Unidos y un riesgo para la visión comunal, mientras que la segunda asume la migración como una posibilidad para la familia más que para la comunidad, al tiempo que son movidos por la inclinación de querer experimentar la aventura del norte. Hoy en día la Selva es una constelación de átomos políticos en pugna por el territorio y la organización, en donde encontramos ejidos prozapatistas, antizapatistas o neutrales, dependiendo de la preferencia política y el nivel de involucramiento con el EZLN.

La rebelión zapatista dejó una tremenda herencia si se analiza desde la perspectiva de una relación interétnica de la gente mestiza y la indígena. Aquellos indígenas que crecieron con padres involucrados en el movimiento zapatista o quienes participaron en él, así como quienes han vivido los cambios positivos, asumieron otros entendimientos sobre la etnicidad, el género, la juventud y los modelos generacionales (Cruz 2012). Ellos son, según Mancina (2011), «los hijos 
o nietos de ejidatarios excasillados», miembros de la primera generación del orgullo étnico en Chiapas y los más interesados en migrar de la selva para seguir manteniendo sus casas y sus familias.

Después del 94, el comon o sentimiento de pertenencia comunitaria perdió fuerza consensual y aquello que mantuvo unidos por casi una década a un gran número de pobladores tseltales y tsotsiles. Con el zapatismo hubo transformaciones importantes pues al pluralizarse la organización política el comon se modificó, unas reforzándolo o promoviéndolo, otras conservándolo, sustituyéndolo, renombrándolo o resemantizándolo, dándole así significados y sentidos distintos. $^{2}$ De 2000 a 2005 varios «selváticos» decidieron irse y enfilar la oleada de chiapanecos en Estados Unidos. La migración internacional indígena se expandió y se convirtió en el nuevo modo de empleo, primero entre los tsotsiles de los Altos, y después para los tseltales y choles de la Selva.

\section{De Chiapas a California, la red tzeltal-chol en San Francisco, Los Ángeles y San José}

Aunque Rus y Guzmán documentaron la presencia de chamulas ${ }^{3}$ en California desde 1996, mis indagaciones permiten establecer que la gente de la Selva siguió a los chamulas, pues varios palencanos ${ }^{4}$ hablantes de chol afirmaron haber llegado antes de 1990. Los pioneros fueron tres hombres jefes de familia palencana que arribaron a Los Ángeles. Vecinos y sobrinos de estos varones confirmaron que sus conocidos y familiares cruzaron la frontera entre 1985 y 1988 (trabajo de campo 2011).

2 Si hago uso de las delimitaciones geográficas anteriores al 94 es porque, de acuerdo con los testimonios de los colaboradores entrevistados, los niveles de adscripción variaban según el terruño (la locación del ejido o comunidad de donde provienen) y la variante lingüística, elementos que definen subregiones dentro de Las Cañadas y, en general, la Selva. Aun así es importante destacar que ellos utilizaban frente a los otros «mexicanos inmigrantes», "chicanos» y «blancos» un nivel de adscripción estatal hacia fuera: el ser «chiapanecos», pero hacia adentro el nivel de adscripción más poderoso era aquel que los unía como «kichanes» primos, hermanos, tíos o cuates de la misma comunidad étnica, elemento que si bien recupera el ser indígena con una ascendencia reconocida, aglutina varias regiones lingüísticas, culturales e históricas dentro del mismo estado de Chiapas. La memoria comunitaria, las raíces lingüísticas y las experiencias de cruce compartidas son los elementos que los identificaban como miembros de la «comunidad kichana migrante» en un país completamente ajenos a ellos.

3 Tsotsiles de la región Altos.

${ }^{4}$ Gente de Palenque, Municipio al norte en la región Selva en Chiapas. Véase el mapa I. 
Los primeros de 20 de noviembre que vinieron acá fueron los Avendaño, luego los Alcázar y luego los Velázquez, eso como en el 85 y 86. Luego vinieron los Miranda por ahí del 88. En 1990 vino mi hermano y cuñado y en el 92 vine yo. Para 1993 el pueblo tenía todavía 70 ejidatarios jefes de familia. Después de que yo vine se dejaron venir 20 personas, todos bien chavos. Del 95 al 2000 el pueblo se vació, puro viejito y mujeres. Ahora no hay jóvenes pues la mayoría se vino o se salió, ahora hay como 30 familias cuando mucho (Job, 32 años, 2011).

Otro grupo originario de la zona norte de la Lacandona, asentado en San Francisco, afirmó que la red empezó a crecer en los noventa, cuando una familia de Palenque enseñó a los Gómez y los últimos a los Velázquez a trasladarse a Estados Unidos. La historia oral afirma que personas de la zona norte de la Selva trazaron escalonadamente la historia migratoria de familias chol y tseltal en San Francisco. Encontré a tres grupos de la Lacandona asentados en San Francisco: los originarios de la zona Norte, los de Estrella y los de la Comunidad Lacandona (Mancina 2011). Efectivamente, como afirmaron los colaboradores, la red empezó en los noventa; creció rápidamente en 10 años y fue expandiéndose y diversificándose con mayor intensidad de 2000 a 2005. Algunos arribaron solos, la mayoría viajó en compañía, otros ya habían estado en la otra costa y posteriormente se mudaron a California.

Los selváticos escucharon del «norte» a través de los centroamericanos que se dirigían a Estados Unidos, guatemaltecos, salvadoreños y hondureños que caminaban por territorio chiapaneco platicando sus historias. Rus y Guzmán (1996) explicaron cómo los chamulas supieron del norte trabajando en las fincas con los guatemaltecos que habían estado ya en los Estados Unidos y que luego ayudaron a los tsotsiles a cruzar la frontera y estos a su vez a los tseltales y choles selváticos.

Yo estaba chamaco, fue mucho antes del 94. Tenía como unos ocho o nueve años, pasaba gente que no era del ejido, hablaban distinto, decían que venía de más pa'bajo, por ahí de Guatemala. Iba pa'l norte y contaba de cómo era allá y cuánto se ganaba. Ya de 14 años, entre los muchachos hablábamos del norte. Los tíos y algunos primos hablaban al único teléfono que había, ya estaban allá (Antonino, 32 años, 2011).

Otra vertiente muestra que varios selváticos de la segunda y tercera generación migratoria fueron guiados por los tsotsiles para llegar a California. Rus y Rus (2008) y Camacho y Lomelí (2009) documentaron las estrategias que han desarro- 
llado los chamulas a partir de su experiencia en el país vecino. A su regreso los chamulas se han desempeñado como transportistas, prestamistas, contrabandistas y en trabajos asociados a la migración indocumentada internacional.

La presencia chol y tseltal en California data de mediados de los ochenta; sin embargo, la mayoría arribó después, entre 1995 y 2005, junto con millones de indocumentados mexicanos a lo largo de Estados Unidos. La historia de la llegada de los selváticos de la comunidad lacandona, hablantes solo de tseltal y uno de maya-lacandón, indica que la salida fue posterior:

Primero vino mi cuñado con su cuñado, unos meses antes de que yo entrara. Luego vine yo con otro tío, un primo y un familiar de mi cuñado. Entramos en 1999. Aquí en San José llevo 11 años. Cuando vino mi tío no había nada de gente de Chiapas. Lucio es mi cuñado y él vino con su cuñado Efrén, ellos durmieron allá arriba, en una iglesia [señalando el cerro], no renta, no nada, ahí dormían. Ya cuando vine acá, entré a trabajar, yo entré de puro plomero, trabajé así ocho años, ganaba 25 la hora, yo ganaba 1500 semanal (Pablo, 41 años, 2011).

Después de la crisis californiana y el endurecimiento de la política antiinmigrante en Estados Unidos se detuvo el aumento de este flujo migratorio protagonizado por la población indígena. Tomó otro rumbo, hacia otros estados donde sus manos eran solicitadas, es decir, en lugares y tiempos donde la producción del capital estaba en apogeo, la costa este: Misisipi, Alabama, Georgia, Florida, Carolina del Sur y Norte, Nueva York, entre otros.

La flexibilidad laboral los atrapó en su lógica móvil, es decir, en una constante búsqueda de salario debido a la fluctuante demanda de trabajo inmigrante en todo el país (cfr. Aquino 2009, Mancina 2011, Gomberg-Muñoz 2011). Al respecto, los hallazgos de Aquino (2010) muestran el alto grado de movilidad de la juventud indígena tojolabal del municipio de Las Margaritas, quienes al enterarse de las ofertas laborales en Misisipi se apresuraron a desarrollar la estrategia de movilización poblacional desde Chiapas, y en menos de un año un buen grupo de jóvenes ya estaba laborando para la atención de una situación emergente a causa de un desastre natural. En el caso de la comunidad de Las Cañadas, Mancina (2011) observa que la migración trasnacional ha movilizado no solo humanos sino capital que ha sido invertido para el desarrollo de las propias comunidades.

La red de tseltales y choles chiapanecos se fue tejiendo cuando arribaron al condado Naranja y el área de la bahía en California; sin embargo, sus contactos incluyen otros estados en Estados Unidos como Oregón, Utah, Texas, Minesota, 
Arkansas, Misisipi, Alabama, Georgia, Florida, Carolina del Sur, Carolina del Norte. Estos tseltales y choles chiapanecos en California son originarios de las tres subregiones de la Selva -Estrella, Norte y Comunidad Lacandona- y las subregiones centrales de los Altos en Chiapas. Su red de contactos es con familiares, vecinos y amigos chiapanecos que viven en ciudades californianas y en otras de Estados Unidos. La red inicia en los pequeños ejidos de Ocosingo, Palenque, Huixtán, Pantelhó, Chilón y Oxchuc y se conecta con su presencia en Sacramento, Salinas, San Francisco, San José, Watsonville, Fresno, Bakersfield, Los Ángeles, Inglewood, Santana, Fullerton, Oxnard, Temecula y Buena Park; ciudades huésped donde han encontrado trabajo o donde viven familiares con quienes hablan a menudo. El Mapa I que a continuación muestro indica lugares de procedencia y llegada en ambos estados.

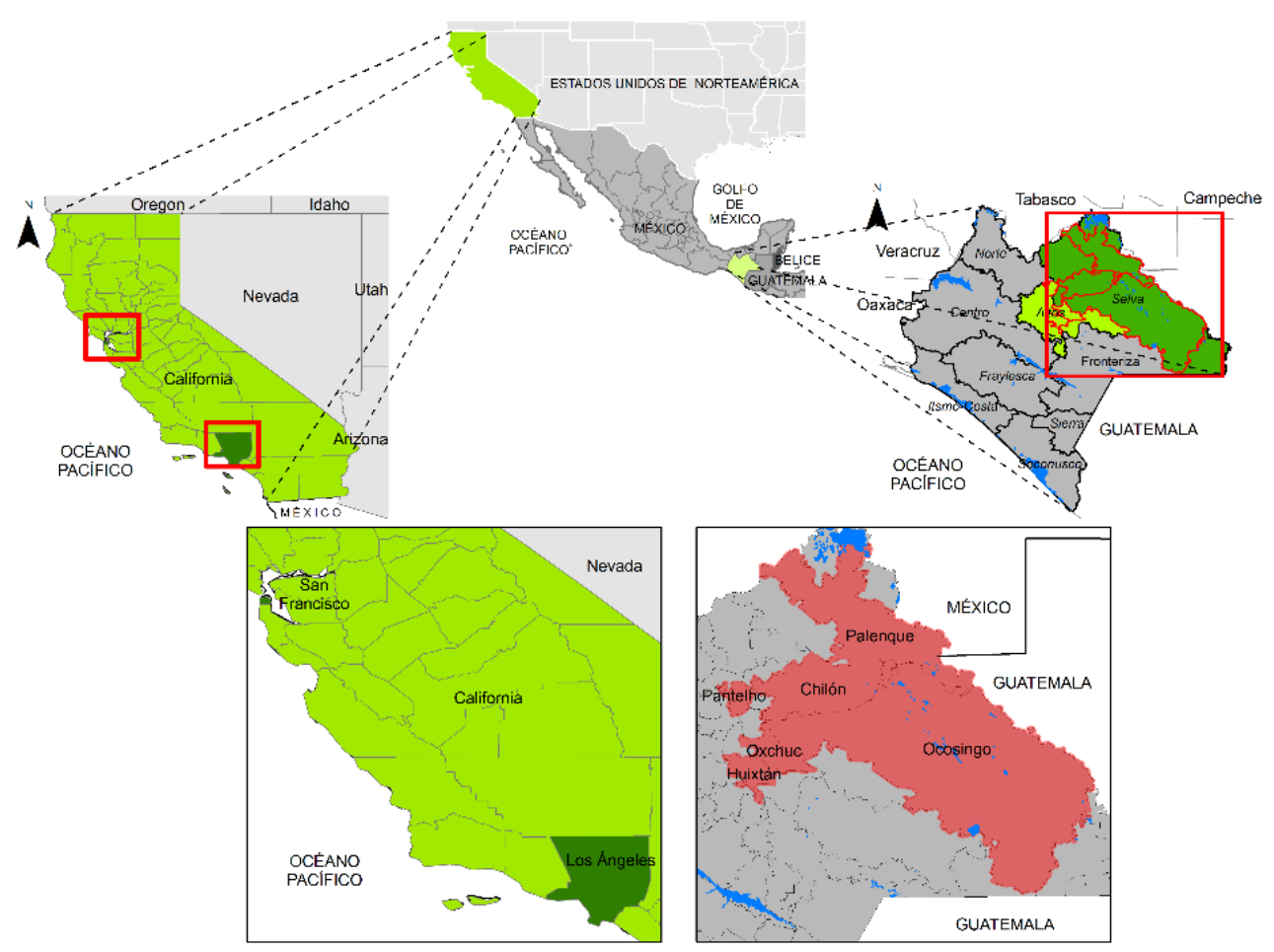

Fuente: elaboración de Emmanuel Valencia, LAIGE-Ecosur, 2016, con base en la información de campo de la autora. 
Dentro de California hay tres grandes grupos localizados en San Francisco, San José y Los Ángeles. La relación más fuerte es entre los grupos de San Francisco y San José porque estas ciudades son más cercanas entre sí, además de que ellos se conocen desde antes de haber migrado y muchos, como comparten el ejido de origen, se encuentran con frecuencia. Quienes viven en Los Ángeles tienen algunos contactos con los de San Francisco y San José, aunque no suelen visitarse porque la distancia entre estas ciudades es de seis horas en auto. No obstante, los que viven en Los Ángeles tienen estrecho contacto con aquellos que habitan en las ciudades del condado Naranja, por lo que viajan constantemente a Fullerton, Santa Ana y Buena Park.

El distrito de Misión, en San Francisco, concentra al grupo más grande y heterogéneo. Como he mencionado sus integrantes son originarios de diversos ejidos de Ocosingo y Palenque, por lo que existe variedad lingüística, cultural y política. La poderosa presencia de gente de Centroamérica en el distrito de Misión, especialmente la salvadoreña, ha ayudado a los chiapanecos a integrarse a esa «ciudad santuario» (Ridgley 2008). Desde la llegada de refugiados centroamericanos, a mediados de 1980, el movimiento santuario abrió muchas opciones de habitar y experimentar San Francisco como «ciudad refugio» más abierta y protegida en términos culturales, políticos y legales. A diferencia de lo anterior, Los Ángeles y San José son ciudades que, para la comunidad migrante latina, actúan de forma diferenciada de acuerdo con los grupos que la integren y las comunidades étnicas que la habiten por zonas. Por la comodidad y el nivel de navegación en San Francisco la comunidad indígena tseltal y cholano-tseltal es la más abierta, tranquila y libre. Son también el grupo mejor integrado porque se han involucrado con la dinámica urbana gracias al gran número de gente indígena latinoamericana que vino antes que ellos, como los guatemaltecos y recientemente los yucatecos. Aunque sus oficios son variados, una buena parte de ellos trabaja en restaurantes y otros en la construcción. Igual que otros migrantes se fueron primero a cada esquina de la calle César Chávez a esperar día a día al nuevo «patrón».

El grupo menos consolidado se localiza en el sureste de San José, California. Los inmigrantes asiáticos, especialmente vietnamitas, arribaron antes a esta área. La comunidad vietnamita inmigrante en San José es la más grande en todo el mundo. Tienen redes de trabajo muy fuertes y controlan negocios locales así como los mercados de fruta, verduras y té. Ellos han contratado inmigrantes latinos para sus restaurantes y supermercados, entre ellos a los tseltales originarios 
del corazón de la Selva. Estos, cuando arriban a San José, encuentran también redes de apoyo centroamericanas; es común que compartan la renta con guatemaltecos y salvadoreños, aunque también con mixtecos y yucatecos. Es el grupo indígena más pequeño, aunque muy diverso: lo conforman tseltales de la zona Norte, lacandones, tseltales y tsotsiles de los Altos. Como única comunidad muy pronto las diferencias culturales salen a la luz, particularmente las lingüísticas y políticas que los dividen en pequeños grupos. La adaptación de los jóvenes tseltales a la comunidad inmigrante latina es débil. Para ellos se define primordialmente a partir de la lógica laboral, la cual es extremadamente inestable y flexible. Entre ellos observé tres diferentes subgrupos que puedo interpretar, más allá de las diferencias de origen, por su experiencia posmigración, esto es, a partir de su adaptación e integración a la ciudad: i) el religioso, ii) el establecido y iii) el disperso. El primero, un grupo pequeño, está conformado por aquellos que se convirtieron a la religión cristiana una vez llegados a San José e integrados a la comunidad salvadoreña que les brindó un fuerte apoyo. La mayoría cuenta con trabajo seguro y bien pagado. Viven en mejores situaciones, pues están acompañados por sus esposas tseltales y cuentan con hijos nacidos en California. El segundo subgrupo es el más grande y sus miembros vienen del mismo ejido localizado en el corazón de la selva; muchos de ellos son familiares y trabajan en la industria de la jardinería, la cual es dirigida por inmigrantes mexicanos de Guadalajara, Michoacán y Querétaro. La mayoría son jóvenes solteros o adultos jóvenes que viven solos porque sus esposas se quedaron en Chiapas. El último subgrupo es el más pequeño y el menos integrado. Se conforma por varones mayores, dos de ellos son los pioneros y otros dos son jóvenes. Estos sufren mucho debido a que tienen extrema dificultad para encontrar trabajo y para conservarlo. Son personas muy solitarias, algunos alcohólicos, otros drogadictos y uno de ellos ya vive en situación de calle.

El último grupo está localizado en Los Ángeles, California. Esta comunidad no es tan grande como la de San Francisco, pero se ha hecho muy fuerte. El grueso de ellos habla ch'ol y tseltal porque vienen de Palenque y Chilón, municipios del norte del estado. Esta comunidad, aunque vive en el centro de Los Ángeles, tiene mucha conexión con otros tseltales que radican en Fullerton, Santana y otras áreas fuera de la ciudad. Con el proceso de gentrificación ahora comparten uno de los espacios más peligrosos de la ciudad con salvadoreños, guatemaltecos y afroamericanos. Se observa que los choles que viven en los barrios centroamericanos más consolidados se encuentran mejor acomodados que aquellos que 
viven en los espacios compartidos con la comunidad afroamericana de clase baja y latina, en donde las disputas entre las pandillas de los «rojos» y «azules» están a la orden del día. Desde su arribo la mayoría de choles y tseltales han trabajado para la industria textil. Aun cuando se conocen entre ellos o han oído hablar uno del otro viven juntos en grupos familiares, pero no comunales. El tamaño de la ciudad no les permite frecuentarse mucho, especialmente si no cuentan con automóvil. Suelen hablarse por teléfono, así como «chatear»y «textear». También son comunes los envíos de dinero para algún «alivio». Cada fin de semana, cuando hay tiempo para descansar, suelen llamar por teléfono a sus paisanos que viven en la otra costa estadounidense o en otro estado. La mayoría de las llamadas derivan en conversaciones sobre los familiares, vecinos o conocidos. Es común informar sobre las salidas nuevas de los ejidos o bien los retornos.

El mapa II detalla la red indígena chiapaneca desde Chiapas hasta el lugar de su asentamiento en el momento de la entrevista. Me interesa demostrar los nodos, vínculos y relaciones que comparten.

Mapa II. Red indígena chiapaneca: nodos, vínculos, flujos.

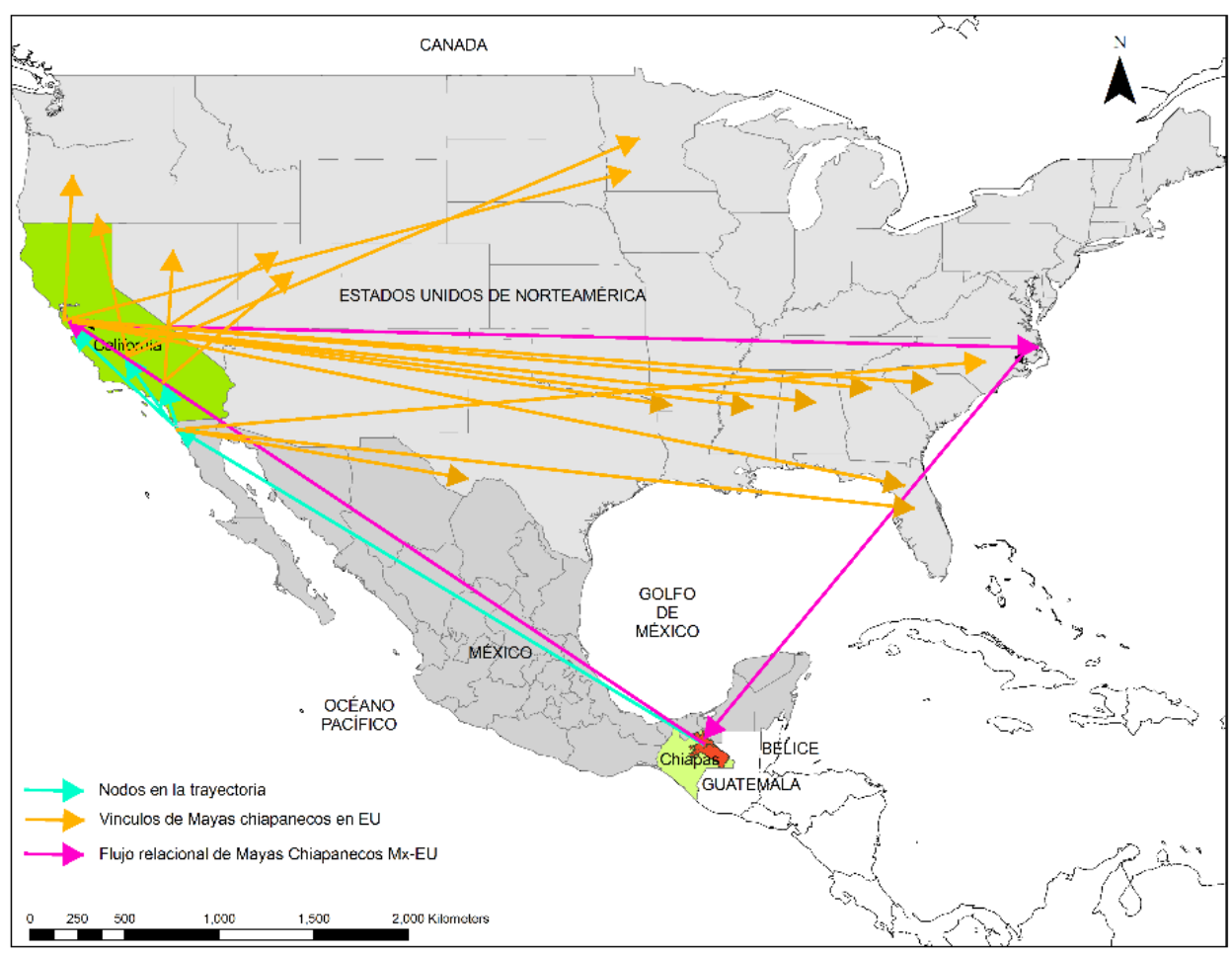

Fuente: elaboración de Emmanuel Valencia, LAIGE-Ecosur, 2016, con base en la información de campo de la autora. 
La trayectoria migratoria se compone de dos puntos dentro de México: Tabasco y Tijuana. Después en California, las tres ciudades de arribo registradas con mayor número de tseltales y choles chiapanecos: Los Ángeles, San José y San Francisco. De estas, en San Francisco existe una fuerte dinámica de intercambio telefónico, visita y envíos hacia muchas otras ciudades de California y sus alrededores. De San José y Los Ángeles hacia otros lugares también están vivos los lazos.

Las nuevas experiencias se resumen en los aprendizajes de otras lógicas: la urbana, la inmigrante, la indocumentada, la obrera, la multicultural, la latina y, por supuesto, la estadounidense; todas aquellas que no remiten a su pasado rural, campesino, indígena, ladino, mestizo, chiapaneco. La relativa integración a su nueva cotidianidad nos conduce a enmarcar su nueva visión del mundo ligando a la vez diferentes lugares y lógicas.

\section{Experiencias migratorias de tzeltales y choles en California}

Las experiencias migratorias son todas las acciones que tienen lugar desde el territorio de origen hasta la comunidad receptora. Aquí las presento organizadas según los arreglos del viaje, los usos de la tecnología y las formas de comunicación, las remesas, el envío de bienes y el multilingüismo. Con ello indico los múltiples marcos referenciales presentes en la experiencia migratoria, incluidos el terruño, la ciudad de acogida y los circuitos y flujos (Faist 2005, Vertovec 2004).

Los entrevistados se dijeron traídos por un familiar y muchos de ellos hicieron el viaje con otro familiar o amigo del mismo pueblo. Fueron invitados a venir a los Estados Unidos por el padre, tío, hermano, cuñado o primo. Los familiares pagaron al coyote y les prestaron dinero para prepararlos y conducirlos en su viaje, así como para su nuevo establecimiento. Como Mancina (2011) señala, estos hombres, como sujetos neoliberales, se ocupan del desarrollo económico de sus pueblos, pues al ser ellos quienes invierten en los viajes de las generaciones subsiguientes están haciéndose responsables de asuntos que competerían al Estado.

Muchas veces el conocimiento de sus familiares fue enseñado y aprendido vía telefónica. Otras veces consultaron a personas experimentadas antes de emprender el viaje. 
Tenía dudas, así que me fui caminado de mi casa a visitar a un tío lejano. Él vive solo desde que regresó. Yo sabía que él me iba a ayudar. ¿Qué pasó?, me dijo y le pregunté cómo era allá. Él me dijo que era muy duro, que mejor no fuera. Pero le dije que me dijera cómo ir. Entonces me dijo, pues si ya lo tienes decidido. Me dijo cómo ir vestido, qué llevar, cómo iba a cruzar, me dio el número de un coyote en Tijuana, me dio dinero y me regaló unas botas para el cruce (Tolomeo, 24 años, 2011).

No solo los familiares tienen conocimiento de la migración, sino otros que comparten ayuda o preparan y guían al novato. Entre los tsotsiles de Chamula existen ya chamanes o brujos que ofrecen un ritual para predecir el éxito potencial de los hombres jóvenes antes de dejarlos abandonar sus hogares. Esto pasa con mayor regularidad en los pueblos de la región Altos, especialmente en San Juan Chamula:

Aquí ya tenemos muchos brujos y brujas que están ayudando a los jóvenes a irse. El joven va a consultar para ver si lo pueden ayudar en el cruce, entonces les hacen un trabajo, «los limpian» y los checan. Ellos tienen que regresar a esperar en su casa unos días. La señal está en los sueños. Se ve si van a cruzar o no. Si no se sueña bien entonces el joven no debe ir. Tiene que regresar con el chamán, pero es mejor que no vaya porque va a sufrir y no va a pasar (líder tsotsil, cabecera San Juan Chamula, 2010).

Cuando la familia del joven sabe y está de acuerdo con la decisión de migrar, la persona que más lo apoya es la madre, aun cuando es ella la que va a sufrir más. Ella le prepara comida, especialmente bolas de masa. Aunque la masa se ponga agria o le crezca moho, puede ser tomada al mezclarla con agua. El resultado es la bebida cultural chiapaneca conocida como pozol. Para el viaje de los jóvenes tseltales migrantes, las madres preparan bolas de pozol, tostadas y algunas porciones de carne.

Los coyotes en Tijuana saben de los chiapanecos y les agradan porque para ellos son los «pollos» más redituables, puesto que ellos «sí saben caminar en la montaña». Los coyotes ven a los chiapanecos fuertes y con mejores habilidades para identificar animales peligrosos y evadirlos sin gritar o ser mordidos por ellos; además, también saben del pozol y creen que esta bebida es adecuada para aquellos que pretender cruzar el desierto.

Ahora ya hay polleros de Chamula que están llevando a los tseltales y a otros directamente a los Estados Unidos. Han creado su propio negocio y ayudan a los chiapanecos a cruzar el desierto (Freyermuth-Enciso et al. 2007). De ambos lados 
de California y Chiapas hay gente trabajando en el proyecto de traslado de los próximos migrantes. Esta gente experimentada conoce las reglas y los tiempos, y le enseñan cada paso a los novatos.

Llamé a mi hermano en San José, California, él me dio el nombre del coyote en Tijuana, el oaxaqueño. Me dijo el nombre del hotel, me dijo que llevara atún, pan, tostadas, mucha agua. Fui en colectivo a Palenque, luego a Tabasco, ahí en avión a México y luego a Tijuana. Llegando tenía que bajarme del avión y agarrar un taxi y decirle el nombre del hotel al taxista, ahí ese hotel es pa' puros migrantes que van a cruzar. Ahí, llegando a esperar que apareciera el coyote. Duré quince días pa' cruzar, nos regresaron tres veces, ya no podía más, mi hermano me llamaba. Cuando crucé, el coyote le llamó a mi hermano, estábamos en Los Ángeles (Bartolo, 26 años, 2011).

Después de cruzar la frontera, envían remesas cada mes por los primeros dos o tres años. Pasado ese periodo, las remesas disminuyen, especialmente si ya pagaron la deuda de su viaje, si construyeron una casa o si invirtieron en algún ranchito o terreno. Solo envían remesas a lo largo de los siguientes años en caso necesario, si un familiar está enfermo, si la familia requiere dinero para una ocasión especial o como regalo en alguna fecha significativa o algún cumpleaños. Algunos de ellos están a cargo de la educación de sus hermanas o hermanos más jóvenes y siguen enviando remesas para que estos continúen sus estudios.

El envío de bienes es una práctica trasnacional activa. Quien vaya de regreso a México llevará fotos impresas, cartas, mensajes, regalos electrónicos y dinero para la familia. Pantallas, iPod, computadoras, ropa, perfumes y cremas son algunos de los productos más comúnmente enviados por ellos a sus familiares en los ejidos.

De vez en cuando los que están en California pedirán alguna cosa especial a alguien que hará un viaje y se lo pueda llevar fácilmente. Nuevamente las fotos impresas son usuales pues actualizan la memoria familiar y comunitaria. Comestibles como masa, achiote, queso, café y pinole son altamente valorados y se convierten en peticiones frecuentes y muy apreciadas entre ellos.

\section{Aprendizajes, adopciones y adaptaciones culturales}

Después de migrar, estos jóvenes cambian sus expectativas de vida. Una de las nuevas interpretaciones adquiridas es pensarse, sentirse y actuar en tanto jóve- 
nes solteros y lejos del panóptico comunitario, institucional y adulto. El estilo de vida californiano urbano a tono con el consumo y la moda les ofrece una amplia apertura cultural y social; la juerga y la soltería son prácticas juveniles dinámicas que definen mucho de su actuar allá. Para ellos es deseable gastar sus ingresos yendo al cine con sus novias o a los clubes con sus amigos, jugando futbol y divirtiéndose en grupo. Les gusta ir de compras y gastan mucho dinero en teléfonos celulares, iPod, cámaras, computadoras, carros y bicicletas, etc. Debido a que sus expectativas de vida no están enfocadas a la unión matrimonial o de pareja ni a tener hijos se concentran en el disfrute del día a día y quieren alargarlo lo más posible.

Estos jóvenes aprendieron a trabajar en el campo cuando eran niños, con sus abuelos, padres y tíos. Este conocimiento les permitió encontrar empleos temporales en los campos de California cuando llegaron por vez primera. Debido a los bajos salarios que reciben en la agricultura tanto en California como en Chiapas, y a sus expectativas, estos jóvenes ya no consideran la opción de trabajar en el campo. Se esfuerzan entonces por encontrar colocación en sectores que signifiquen un mejoramiento de estatus. La diferencia entre ellos y cientos de miles de migrantes mexicanos que han considerado el trabajo agrícola como una opción es cultural, porque estos indígenas han labrado la tierra desde que eran niños. Emplearse como albañiles, meseros, jardineros o en la industria textil es una alternativa para ellos; o bien en el sector informal, vendiendo papeles falsos o música y películas piratas que es incluso más cotizado que ir persiguiendo las temporadas de cosecha para ir a piscar.

La vida citadina les hace enfocarse en el día a día, aunque también invierten a pequeña escala en los ejidos de Chiapas. Muchos han comprado ganado y construido potreros. Con esto tratan de ascender en su nivel social, dejar atrás su identificación como campesinos y jornaleros. Ser migrantes y obreros o empleados de alguna compañía en Estados Unidos les permite «comprar» o invertir en sus tierras natales y aspirar a convertirse en pequeños ganaderos en Chiapas, figura con poder y mucho estatus social. De ahí que en sus conversaciones un tema recurrente sea hablar sobre el número de cabezas de ganado que poseen, las extensiones de tierra adquirida, o bien el número de recámaras de su nueva casa.

La migración se convierte en una necesidad si el varón es jefe de familia y necesita continuar desempeñando su rol de género, o si cuenta con cierta posición social o le ha tocado algún cargo en la comunidad y necesita dinero para enfren- 
tarlo. La generación y el género son factores que juegan papeles prioritarios en la decisión de partir. Estos factores se reconfiguran con la experiencia migratoria internacional y los marcos referenciales se traslapan al experimentar-construir la bifocalidad (Vertovec 2004) originada por el contraste entre los sistemas de género tradicionales que estructuran la enseñanza y la lógica indígena frente a los ampliamente revolucionados en las ciudades californianas; especialmente en San Francisco, donde las identidades de género y sexuales rebasan las prácticas ancladas a la heterosexualidad y la monogamia. Aun con su experiencia californiana estos jóvenes viven con la memoria de la comunidad de origen y luchan por integrarse a la lógica de la comunidad receptora.

Mientras están en California regularmente se involucran con muchachas no indígenas y tratan de tener una relación estable, pero es común que enfrenten un conflicto cultural porque las mujeres con las que salen no son tan tradicionalistas como las de su comunidad en Chiapas. Cuando intentan tener una relación seria con mujeres no indígenas en Estados Unidos ven que estas mujeres no muestran el grado de compromiso que ellos esperan para su relación (aun después de haber tenido juntos un hijo); así lo señalan Jerónimo y Mateo en una conversación sobre las diferencias entre «allá y acá»:

Aquí no puedes tener una novia bien pues ellas siempre buscan dinero. Tienes que tener carro y eso. Acá no más de un rato. Aquí cuando vives con ella no se dice casado, solo novia, allá si te vas a vivir juntos son marido y mujer. Allá una mujer casada es una mujer de hogar, acá como los dos trabajan, cuando ella ya no quiere seguir la relación nomás se va. Aquí es muy diferente. Cuando yo me vine a vivir con mi novia le dije pues en algunos años nos vamos a Chiapas juntos, ¿no? Y ella me dijo que no. Le pregunté: «¿Estás enamorada de mí?» «No me muero por ti, hay que vivir la vida». Allá no, allá cuando tienes la mujer es tu «vieja», ya te casaste y es pa' siempre. Acá no puedes decir nada. Si le tocas el pelo te lleva la policía. Aquí está difícil, es diferente (Jerónimo, 22 años, 2012; Mateo, 25 años, 2012).

Estas experiencias tienen un importante impacto en la identidad étnica porque estos jóvenes aprenden a tener relaciones más flexibles, menos comprometidas al no estar bajo el yugo de la comunidad, el panóptico que regula el control social. Esto les abre el panorama en términos de relaciones amorosas y relativiza sus expectativas de pareja y de futuro. A partir de las relaciones sostenidas en California ellos comparan constantemente el «aquí»y el «allá», el «antes» y el 
«después». Sobre todo es su representación de mujer la que cambia y por lo tanto sus parámetros de involucramiento.

La mayoría de las mujeres con quienes ellos salen son inmigrantes de lugares rurales del norte de México, con otras costumbres y expectativas. Es común que ellas tengan más tiempo viviendo en California; algunas son mayores que ellos, otras son madres solteras o separadas, y las hay también solteras.

Dentro de Chiapas no es común ver parejas de mestizos e indígenas porque regularmente se practica la endogamia. Al migrar a California esto cambia ya que ellos se vuelven parte de la comunidad compuesta por otros mexicanos y latinos, donde tienen la posibilidad de salir con muchachas no indígenas. A los jóvenes les gusta esto porque evitan cierto nivel de discriminación cultural. El racismo en México es tan intenso que los indígenas son siempre el blanco; en términos culturales son los «otros». Una vez que llegan a las ciudades estadounidenses dejan de ser indígenas y se convierten en migrantes indocumentados latinos. Aunque todavía enfrentan el racismo es más frecuente que provenga de los latinos y de otros mexicanos.

En las comunidades los tseltales suelen casarse entre familiares, pero cuando emigran se casan con mujeres de otros orígenes. Esto tiene un impacto muy fuerte en la estructura de la familia indígena y en su herencia. Antes de que empezara la migración indígena era común que los xuts o los k'och, benjamines de cada familia, se quedaran a cuidar a los padres y no pudieran dejar el pueblo (Sánchez 2009); en recompensa recibirían la herencia y la casa de los padres, se casarían con una mujer tseltal, habitarían la casa de la familia y trabajarían la tierra heredada. Con la migración a los Estados Unidos la estructura familiar ha sido afectada significativamente: los padres se quedan en casa solos y las mujeres están empezando a migrar a las ciudades de Chiapas porque los hombres jóvenes dejaron las comunidades y no están seguros de querer regresar a casarse con una mujer tseltal.

\section{Conclusiones}

La experiencia migratoria de tseltales y choles de Chiapas a California muestra un vasto aprendizaje cultural. Muchos de estos aprendizajes modifican sus visiones de mundo porque es un proceso que tiene un impacto multidimensional a nivel 
identitario. Su pasado multicultural incrementa debido a su relativa integración y adaptación en diferentes grupos sociales y comunidades en California.

Al tiempo que son inmigrantes en los Estados Unidos son miembros de su comunidad (el ejido chiapaneco), pero también de la nueva comunidad que han construido en California; aunque algunas veces esta se expresa como una conexión-expansión de la comunidad natal (Chiapas-California). A la vez que son miembros de la comunidad inmigrante compuesta por indocumentados y latinos son miembros de la clase trabajadora indocumentada.

La experiencia migratoria de los jóvenes indígenas cuenta con una multifocalidad y exige atención en distintos niveles. No es una tarea fácil porque han enfrentado y aprendido a transitar de su modo de vida indígena a la lógica mestiza dentro de México y Chiapas, y después de migrar tienen que aprender a navegar entre las comunidades latina y mexicana, al igual que en la estadounidense. Así, estos sujetos han ampliado su visión de modo tal que les permite cambiar de un escenario a otro y ser exitosos a pesar de los requerimientos subjetivos que esto conlleva (Faist 2004, 2005, Vertovec 2004).

La etnicidad y otros atributos específicos de la gente del sur mexicano han diversificado los patrones de la migración internacional mexicana de los últimos 30 años. El pueblo indígena chiapaneco en Estados Unidos es mayormente joven, masculino, multilingüe, campesino y mejor capacitado que el que conformaron los varones de generaciones previas. Para ellos la migración internacional es una experiencia desafiante porque inevitablemente enfrentan problemas de integración y adaptación en las ciudades estadounidenses. Sus experiencias migratorias hablan de confrontaciones desde una posición subalterna, previa y posterior a su salida.

La identidad étnica no termina con este proceso de reenmarcamiento cultural, ni en la nueva adaptación o integración social. Recordemos que los actores sociales pueden «manipular» su identidad cuando están fuera de su grupo de origen. Desde el punto de vista de la población rural e indígena migrante, la habilidad como grupo étnico para cambiar de un grupo social a otro significa que son capaces de «ser activos» en más de un grupo. Esto es muy común entre indígenas mexicanos que han sido parte de una vida bicultural por cientos de años. La identidad se convierte en un recurso para el ejercicio del poder colectivo al ampliar los antecedentes de su pasado cultural en los nuevos escenarios. La identidad étnica puede algunas veces ser un medio para la acción, aun cuando sea inseparable de la historia cultural comunitaria. 


\section{Referencias bibliográficas}

Aquino Moreschi, Alejandra, 2009, «Entre el 'sueño zapatista' y el 'sueño americano': la migración a Estados Unidos vista desde las comunidades zapatistas», Migración y desarrollo, 13, pp. 79-95.

Aquino Moreschi, Alejandra, 2010, «Migrantes chiapanecos en Estados Unidos. Los nuevos nómadas laborales», Migraciones internacionales, 5(4), pp. 39-68.

Camacho Velázquez, D. y Arturo Lomelí, 2009, «Procesos migratorios de chiapanecos hacia el norte: causas y consecuencias», en Gabriela Freyermuth-Enciso y Sergio Meneses (coords.), De crianzas, jaibas e infecciones: indígenas del sureste en la migración, México, CIESAS, pp. 81-107.

Cruz Salazar, Tania, 2012, «La norteada juvenil: representaciones de la migración tsotsil» en Elissa Rashkin y Norma Esther García Meza (coords.), Escenarios de la cultura y la comunicación en México: de la memoria al devenir cultural, Jalapa, Universidad Veracruzana, pp. 38-89.

Faist, Thomas, 2004, «The Border-Crossing Expansion of Social Space: Concepts, Questions and Topics», en Thomas Faist y Eyüp Özveren (eds.), Transnational Social Spaces. Agents, Networks and Institutions, RU/EUA, Ashgate, pp. 1-36 (Research in migration and ethnic relations series).

_- 2005, «Espacio social transnacional y desarrollo: una exploración de la relación entre comunidad y Mercado», Migración y Desarrollo, 5, pp. 2-34.

Freyermuth-Enciso, Graciela, Sergio Meneses y Germán Martínez (coords.), 2007, El señuelo del norte: migración indígena contemporánea, San Cristóbal de Las Casas, Chiapas, Consejo Estatal de Población Chiapas/Fondo de Población de las Naciones Unidas, Asesoría, Capacitación y Asistencia en Salud, pp. 22-223.

Gomberg-Muñoz, Ruth, 2011, Labor and Legality: An Ethnography of a Mexican Immigrant Network, (Issues of Globalization: Case Studies in Contemporary Anthropology), Oxford, Oxford University Press.

Leyva Solano, Xóchitl, 2002, «Transformaciones regionales, comunales y organizativas en Las Cañadas de la Selva Lacandona (Chiapas, México)», en Shannan L. Mattiace, Rosalva Aída Hernández y Jan Rus (eds.), Tierra, libertad y autonomía: impactos regionales del zapatismo en Chiapas, México, CIESAS/IWGIA, pp. 57-82.

Mancina, Peter, 2011, «Crisis-management: Tseltal-Indigena transnational migration and the Foucauldian apparatus», Dialectical Anthropology, 35(2), pp. 205- 225.

Ridgley, Jannifer, 2008, "Cities of Refuge: Immigration Enforcement, police, and the Insurgent Genealogies of Citizenship in U.S. Sanctuary Cities», Urban Geography Journal, 29(1), pp. 53-77.

Rus, Jan, 2010, The End of the Plantations and the Transformation of Indigenous Society in Highland Chiapas, Mexico, 1974-2009, tesis de doctorado, University of California Riverside.

Rus, Jan y George Collier, 2002, «Una generación en crisis en los Altos de Chiapas: los casos de Chamula y Zinacantán, 1974-2000», en Shannan L. Mattiace, Rosalva Aída Hernández y Jan Rus (coords.), Tierra, libertad y autonomía: impactos regionales del zapatismo en Chiapas, México, CIESAS/IWGIA, pp. 157-199. 
Rus, Jan y Salvador Guzmán López, 1996, Jchiiltik ta slumalKalifornia: slo'ilik Santos xhi'uk Marian xchi'uk Xun Gómes López, chamulas en California: El testimonio de Santos, Mariano y Juan Gómez López, México, Instituto de Asesoría Antropológica para la Región Maya.

Rus, Diane y Jan Rus, 2008, "La migración de trabajadores indígenas de los Altos de Chiapas a Estados Unidos, 2001-2005: el caso de San Juan Chamula», en Daniel Villafuerte Solís y María del Carmen García Aguilar (coords.), Migraciones en el sur de México y Centroamérica, México, Miguel Ángel Porrúa/UNICACH/FLACSO-Costa Rica/OIM-NCCR, pp. 343-382.

Sánchez, Irene, 2009, «Entre arraigo y movilidad: el xut en la familia tseltal contemporánea de El Corralito, Oxchuc, Chiapas», tesis de maestría inédita, CIESAS.

Vertovec, Steven, 2004, «Migrant transnationalism and modes of transformation», International Migration Review, 38(3), pp. 970-1001. 